\title{
Respostas morfofisiológicas das plantas forrageiras sob manejo de cultivo e pastejo:
}

\section{Uma revisão}

\author{
Morphophysiological responses of forage plants under crop and grazing management: A review \\ Respuestas morfofisiológicas de plantas forrajeras bajo manejo de cultivos y pastoreo: Una revisión
}

Recebido: 23/04/2021 | Revisado: 03/05/2021 | Aceito: 07/05/2021 | Publicado: 22/05/2021

\author{
Cleber Pereira Alves \\ ORCID: https://orcid.org/0000-0002-8796-6945 \\ Universidade Federal Rural de Pernambuco, Brasil \\ E-mail: cleberp.alves@hotmail.com \\ Baltazar Cirino Júnior \\ ORCID: https://orcid.org/0000-0002-0719-611X \\ Universidade Federal Rural de Pernambuco, Brasil \\ E-mail: btzsilvajunior@gmail.com \\ Ana Karlla Penna Rocha \\ ORCID: https://orcid.org/0000-0002-4717-6359 \\ Universidade Federal Rural de Pernambuco, Brasil \\ E-mail: karllapenna@hotmail.com \\ Domingos Sávio Marques de Menezes Vieira \\ ORCID: https://orcid.org/0000-0003-3576-5647 \\ Universidade Federal Rural de Pernambuco, Brasil \\ E-mail: domingosagronomia@outlook.com \\ Danielle da Silva Eugênio \\ ORCID: https://orcid.org/0000-0002-1980-2180 \\ Universidade Federal Rural de Pernambuco, Brasil \\ E-mail: nielle_eugenio15@hotmail.com \\ Maurício Luiz de Mello Vieira Leite \\ ORCID: https://orcid.org/0000-0003-4241-241X \\ Universidade Federal Rural de Pernambuco, Brasil \\ E-mail: nopalea21@yahoo.com.br
}

\begin{abstract}
Resumo
A pecuária brasileira promove segurança alimentar e estabilidade econômica para os produtores, representando um elevado número de estabelecimentos no agronegócio nacional, com forte participação no produto interno bruto do país, além da geração de empregos. As pastagens são a principal fonte de alimentos para os ruminantes, contudo nem sempre são manejadas adequadamente. As interações que ocorrem no ecossistema pastagem são dinâmicas e complexas, envolvendo as relações entre pasto, animal, solo e meio ambiente. A gestão sustentável de uma pastagem visa conciliar os aspectos quali-quantitativos da produção de forragens com a eficiência da resposta animal por área. As práticas de manejo de cultivo e a intensidade de pastejo são dois fatores que promovem diversas alterações na morfofisiologia dos pastos, sendo que essas respostas variam, primordialmente, em função da espécie vegetal, do genótipo, do sistema de pastejo adotado, da pressão de pastejo e da nutrição do solo, influenciando diretamente na alocação e absorção de seiva, crescimento aéreo e radicular, interceptação luminosa, eficiência fotossintética e produção de fitomassa. Adequações e tomada de decisões são essenciais para otimização dos sistemas de produção, principalmente por meio de modificações no ambiente, com o intuito de proporcionar êxito na produção agrícola, evitando prejuízos econômicos e ambientais. Dessa forma, objetivou-se com essa revisão discorrer sobre a influência da modificação do ambiente nas respostas morfofisiológica das plantas por meio das práticas de manejo e ajustes na intensidade de pastejo, bem como relatar o impacto dessas na dinâmica de crescimento das culturas forrageiras que compõem a pastagem.
\end{abstract}

Palavras-chave: Forragem; Interação planta-solo-animal; Pastagem.

\footnotetext{
Abstract

Brazilian livestock promotes food security and economic stability for producers, representing a large number of specified agribusiness, with strong participation in the gross domestic product, as well as job creation. Pastures are the main source of food for ruminants, however they are not always managed properly. The interactions that occur in the pasture ecosystem are dynamic and complex, involving the relationships between pasture, animal, soil and environment. The sustainable management of a pasture aims to reconcile the qualitative and quantitative aspects of forage production with the efficiency of the animal response by area. Cultivation management practices and grazing intensity are two factors that promote several changes in the morphophysiology of pastures, and these responses vary,
} 
primarily, depending on the plant species, genotype, grazing system adopted, grazing pressure and soil nutrition, directly influencing sap allocation and absorption, aerial and root growth, light interception, photosynthetic efficiency and phytomass production. Adjustments and decision making are essential for optimizing production systems, mainly through changes in the environment, in order to provide success in agricultural production, avoiding economic and environmental losses. Thus, the aim of this review was to discuss the influence of environmental modification on plant morphophysiological responses through management practices and adjustments in grazing intensity, as well as to report the impact of these responses on the growth dynamics of forage crops, in which they form the pasture.

Keywords: Forage; Plant-soil-animal interaction; Pasture.

\section{Resumen}

La ganadería brasileña promueve la seguridad alimentaria y la estabilidad económica de los productores, que representan un alto número de establecimientos agroindustriales nacionales, con una fuerte participación en el producto interno bruto del país, además de la creación de empleo. Los pastoreos son la principal fuente de alimento para los rumiantes, sin embargo, no siempre se manejan adecuadamente. Las interacciones que ocurren en el ecosistema de pastoreos son dinámicas y complejas, involucrando las relaciones entre pastos, animales, suelo y medio ambiente. El manejo sustentable de una pastura tiene como objetivo conciliar los aspectos cualitativos y cuantitativos de la producción de forrajes con la eficiencia de la respuesta animal por área. Las prácticas de manejo del cultivo y la intensidad del pastoreo son dos factores que promueven varios cambios en la morfofisiología de los pastos, y estas respuestas varían, principalmente, dependiendo de la especie de planta, genotipo, sistema de pastoreo adoptado, presión de pastoreo y la nutrición del suelo, que influye directamente en la distribución y absorción de la savia, el crecimiento aéreo y radicular, la intercepción de luz, la eficiencia fotosintética y la producción de fitomasa. La adecuación y la toma de decisiones son fundamentales para optimizar los sistemas productivos, principalmente a través de cambios en el entorno, con el fin de brindar éxito en la producción agrícola, evitando pérdidas económicas y ambientales. Así, el objetivo de esta revisión fue discutir la influencia de la modificación ambiental en las respuestas morfofisiológicas de las plantas a través de prácticas de manejo y ajustes en la intensidad del pastoreo, así como reportar el impacto de estas respuestas en la dinámica de crecimiento de los cultivos forrajeros que componen el pasto. Palabras clave: Forraje; Interacción planta-suelo-animal; Pastoreo.

\section{Introdução}

A pecuária desempenha importante papel na economia, e é representada em grande parte por pequenos e médios produtores ( $i$. e e. agricultura familiar). O fluxo continuo dos produtos advindos desse setor encontra-se em constante crescimento devido ao aumento populacional, urbanização e elevação da renda dos países produtores (Dutilly et al., 2019). Com o crescimento populacional, a demanda por produtos agropecuários tende a se elevar, principalmente proteínas animais (e. g. leite e carne) (Biglari et al., 2019), refletindo em aumento na necessidade por produtos forrageiros, com o intuito de promover a alimentação animal, em qualidade e quantidade.

Atrelado aos fatores elencados anteriormente, a tendência nas mudanças climáticas e sua variabilidade, traz consigo riscos relacionados à produção agropecuária, principalmente em ambientes quentes e secos (Biglari et al., 2019). As projeções climáticas mostram que as alterações nos padrões de precipitação pluvial e temperatura do ar e do solo para os ecossistemas, influenciam nos recursos disponíveis, bem como em sua utilização (Milhorance et al., 2019).

Nesse cenário, o uso de estratégias que venham a mitigar as influencias edafoclimáticas adversas é de suma importância. Dessa forma, o uso de manejo de cultivo (e. g. adubação, irrigação, etc.) e adequação do pastejo tornam-se práticas relevantes, uma vez que, buscam a otimização do sistema de produção por meio de modificações no ambiente, proporcionando êxito na produção agrícola, sem causar prejuízos econômicos e ambientais (Santos et al., 2011).

O emprego de manejos pode promover alterações morfofisiológicas nas plantas forrageiras, destacando a influência na absorção de água e nutrientes, interceptação luminosa, crescimento aéreo e radicular, eficiência fotossintética, entre outras (Costa et al. 2004). Diante do exposto, objetivou-se com essa revisão, abordar a influência da modificação do ambiente nas respostas morfofisiológica das plantas forrageiras por meio das práticas de manejo. 


\section{Metodologia}

A revisão foi realizada a fim de obter maiores informações sobre a influência da modificação do ambiente nas respostas morfofisiológicas das plantas forrageiras. Para isto, foi realizada buscas nas bases de dados: Science Direct, Google Acadêmico, Periódicos CAPES e SciELO. Para esta revisão narrativa, de cunho qualitativo (Pereira et al., 2018), foi utilizada em sua maioria, artigos publicados em revistas científicas nacionais e internacionais, no entanto, abrangeu também dissertações de mestrado, livros, comunicados técnicos e alguns sites relacionados à área de interesse.

\section{Revisão de Literatura}

\subsection{Fatores que afetam a morfofisiologia vegetal}

A morfofisiologia das plantas forrageiras é afetada principalmente por três fatores, sendo eles o ambiental (i. e. clima e solo), manejo de cultivo e o pastejo animal (Figura 1). Cada fator promove diferentes alterações, a depender da espécie vegetal, do genótipo e intensidade do fator.

Figura 1. Fatores que influenciam as características morfofisiológicas das plantas forrageiras.

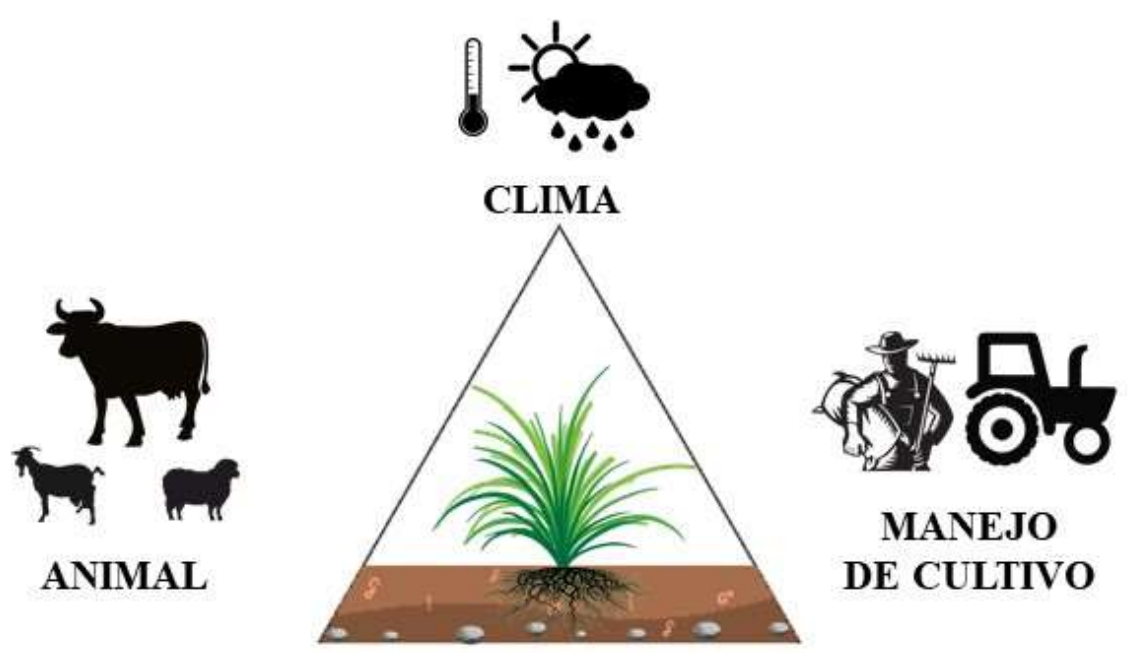

\section{SOLO}

Fonte: Autores.

\subsubsection{Fatores ambientais}

Fatores ambientais (e. g. CO2 atmosférico, temperatura do ar, luminosidade e características do solo) (Figura 2) podem limitar ou favorecer o crescimento das plantas forrageiras, influenciando direta ou indiretamente na absorção e transporte de nutrientes, principalmente dos produtos fotoassimilados. Limitando a adaptação e interferindo, de forma significativa, no rendimento das culturas (Durães et al., 1995). 
Figura 2. Fatores ambientais que promovem modificações nas características morfofisiológicas das plantas forrageiras.

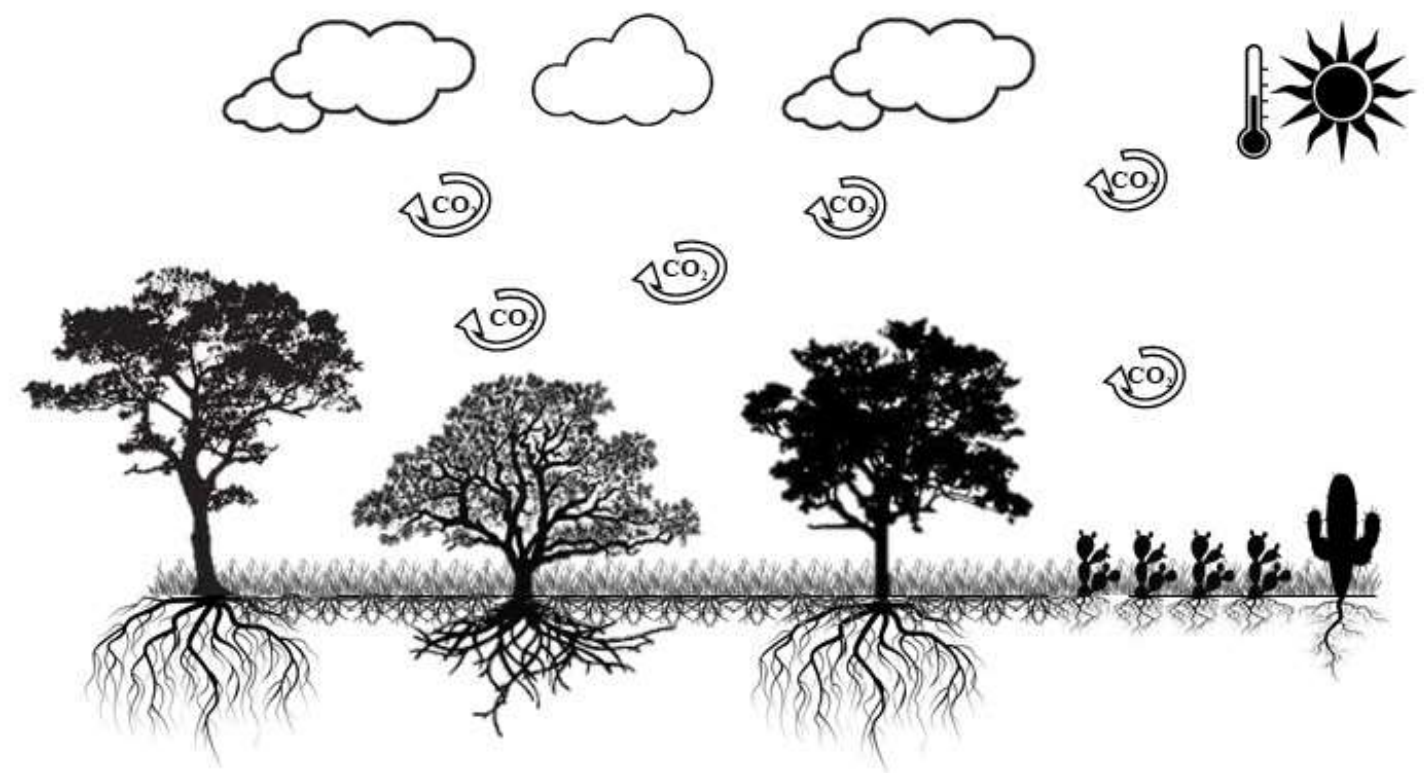

Fonte: Autores.

A área foliar é bastante afetada por diversos fatores associados ao ambiente, os quais influenciam diretamente na fotossíntese e transpiração das culturas, refletindo m seu rendimento final. O aumento de $\mathrm{CO} 2$ atmosférico, por exemplo, promove redução significativa na condutância estomática dos vegetais, reduzindo a transpiração e interferindo na expansão da área foliar, por meio da maior assimilação do carbono a ser utilizado nos processos fotoquímicos, principalmente em cenário de mudanças climáticas (Lovelli et al., 2010).

Sob o aspecto de mudanças climáticas é de suma importância o entendimento do crescimento e desenvolvimento das culturas submetidas a variação na temperatura do ar, já que irá influenciar em alterações nas células e tecidos, afetando a sobrevivência e adaptação dos vegetais (Nascimento et al., 2014). Estudos mostraram que a temperatura do ar afeta o crescimento do mesocótilo e do coleóptilo e a falta de raízes fasciculadas no entorno da semente principal causadora dos baixos índices de sobrevivência de plântulas em ambiente semiárido (Hyder et al., 1971; Dofing \& Schimidt, 1984; Martin et al., 1988; Mozambani \& Bicudo, 2009). As altas temperaturas favorecem alongamento do mesocótilo, enquanto que as baixas temperaturas associadas a menores taxas de radiação promovem um maior comprimento do coleóptilo, sendo a interação fatores ambientais x morfologia responsável direta pela produtividade dessas culturas (Parfitt, 2000), favorecendo a redução na taxa fotossintética, diminuindo a taxa de crescimento (Mozambani \& Bicudo, 2009). Associado às temperaturas, a ausência de luminosidade promove o estiolamento das plantas, baixo desenvolvimento dos cloroplastos e redução na atividade de algumas enzimas (Mozambani \& Bicudo, 2009).

A luminosidade incidente é outro fator limitante na produtividade das culturas forrageiras, podendo haver alterações quanto sua estrutura e composição nutricional. Em condições de sombreamento, as plantas, em sua grande maioria apresentam decréscimo na produção de matéria seca, aumento do teor de fibra e modificações morfofisiológicas, uma vez que respondem de maneira diferente em função de sua tolerância ao sombreamento e as mudanças no nível de irradiância (Soares et al., 2009; Gobbi et al., 2010; Almeida et al., 2015). Por outro lado, a presença de sombra também pode contribuir de forma positiva, visto que algumas espécies apresentam melhor valor nutricional, maior área foliar e maior relação folha/colmo (Soares et al., 
2009). De modo geral, isto acontece quando há a implantação de sistema agrossilvipastoril, considerado uma alternativa potencial, por otimizar a utilização das áreas, proporcionar uma melhoria do microclima, possuir maior aporte de nutrientes e serapilheira, fazendo com que este sistema seja altamente recomendado para recuperação e manutenção de pastagens (Freitas et al., 2013).

Outro fator de extrema importância quando se refere aos aspectos morfofisiológicos das plantas forrageiras é o solo. Para a cultura atingir seu pleno crescimento e desenvolvimento, é necessário que haja a absorção dos nutrientes presentes na solução do solo, através do sistema radicular, por meio de diversos mecanismos (i. e. fluxo de massa, difusão e interceptação radicular) (Rosolem et al., 2003). Para que as raízes apresentem seu desenvolvimento ótimo, as plantas necessitam desenvolver uma pressão de turgescência nas células de elongação, que devem contrabalancear a pressão exercida pelo meio externo. Dessa forma, as características físicas do solo afetam diretamente tal desenvolvimento, principalmente quando os solos são ou estão compactados, devido à redução do oxigênio, aumento da densidade e redução no potencial de água no solo (Nogueira \& Manfredini, 1983). Um dos principais componentes que contribue para a melhoria vegetal, é justamente o preparo do solo, uma vez que está intrinsicamente associado ao desenvolvimento do sistema radicular. Tais preparos incluem o revolvimento do solo, de tal modo que promove diferença na morfologia do sistema radicular (Mello Ivo \& Mielniczuk, 1999).

Se tratando do desenvolvimento e crescimento das plantas, outro elemento de importância é o déficit hídrico, o qual na maioria dos casos promove impactos negativos nos vegetais. As respostas das plantas são dependentes da intensidade, duração e progressão do estresse, bem como o genótipo e a época. Muitas plantas desempenham mecanismos bioquímicosfisiológicos em ajustar osmoticamente suas células quando submetidas ao estresse hídrico. Dentre as respostas das plantas ao estresse, podem ser citados a redução no crescimento, uma vez que se tem um decréscimo nas trocas gasosas, diminuição na área foliar, aumento nos osmoprotetores (e. g. prolina e açucares), e redução no potencial fotossintético (Zilliani, 2015).

Outro estresse que compromete demasiadamente o crescimento e desenvolvimento das plantas forrageiras é o salino. Esse estresse promove a perturbação das funções fisiológicas e bioquímicas das plantas, refletindo em distúrbios nas relações hídricas e na absorção de nutrientes pelas raízes, devido a competição entre os íons presentes. Dentre os distúrbios destaca-se a redução fotossintética, devido a inibição provocada pelo acumulo de íons de $\mathrm{Na}+$ e/ou $\mathrm{Cl}$ - nos cloroplastos, afetando tanto os processos bioquímicos quanto os fotoquímicos, refletindo em redução no crescimento e desenvolvimento das plantas (Gomes et al., 2011).

\subsubsection{Influência do manejo de cultivo na morfofisiologia}

Além dos fatores ambientais, um aspecto determinante para a modificação nas características das plantas forrageiras é o manejo empregado (Cândido et al., 2005). O manejo de cultivo busca a maximização nos níveis de produtividade, através da adoção de práticas que possibilitem melhoria no crescimento e desenvolvimento das culturas (Diniz et al., 2017; Erkossa, Williams \& Laekemariam, 2018).

Na Tabela 1 são apresentadas modificações nas características morfofisiológicas das plantas forrageiras quando submetida aos diferentes manejos de cultivo. 
Tabela 1. Alterações morfofisiológicas das plantas forrageiras submetidas aos diferentes manejos de cultivo.

\begin{tabular}{|c|c|c|c|c|}
\hline Manejo de cultivo & Nome popular & Nome científico & Alteração morfofisiológica & Fonte \\
\hline Densidade de plantio & Capim-tanzânia & Panicum maximum & $\begin{array}{c}\text { Taxa de alongamento foliar e } \\
\text { pseudocolmo }\end{array}$ & $\begin{array}{l}\text { Magalhães et al. } \\
\text { (2011) }\end{array}$ \\
\hline Adubação nitrogenada & Capim-aruana & $\begin{array}{l}\text { Panicum maximum } \\
\text { cv. Aruana }\end{array}$ & $\begin{array}{l}\text { Condutância estomática, taxa } \\
\text { fotossintética, taxa de } \\
\text { alongamento foliar e filocrono }\end{array}$ & $\begin{array}{l}\text { Pompeu et al. } \\
\qquad(2010)\end{array}$ \\
\hline Adubação nitrogenada & Capim-braquiária & $\begin{array}{c}\text { Brachiaria } \\
\text { decumbens } \mathrm{cv} . \\
\text { Basilisk }\end{array}$ & $\begin{array}{l}\text { Densidade populacional de } \\
\text { perfilhos e densidade } \\
\text { volumétrica de forragem }\end{array}$ & $\begin{array}{l}\text { Fagundes et al. } \\
\qquad(2006)\end{array}$ \\
\hline Adubação nitrogenada & Capim-tanzânia & Panicum maximum & Taxa de alongamento foliar & $\begin{array}{l}\text { Lins et al. } \\
\quad(2015)\end{array}$ \\
\hline Adubação fosfatada & Capim-marandu & $\begin{array}{c}\text { Brachiaria brizantha } \\
\text { cv. Marandu }\end{array}$ & $\begin{array}{l}\text { Número de perfilhos, taxa de } \\
\text { crescimento inicial }\end{array}$ & $\begin{array}{l}\text { Rezende et al. } \\
\text { (2011) }\end{array}$ \\
\hline Adubação potássica & Capim-mulato & Brachiaria híbrida & $\begin{array}{c}\text { Número de perfilhos e taxa de } \\
\text { alongamento foliar }\end{array}$ & $\begin{array}{l}\text { Sanchês et al. } \\
\qquad(2013)\end{array}$ \\
\hline Consórcio & Capim-tanzânia & Panicum maximum & Não apresentou alterações & $\begin{array}{l}\text { Lins et al. } \\
(2015)\end{array}$ \\
\hline Consórcio & Palma forrageira & Opuntia stricta & $\begin{array}{c}\text { Fase fenológica, surgimento de } \\
\text { cladódios de terceira ordem }\end{array}$ & Souza (2019) \\
\hline Cobertura morta & Milheto & Pennisetum glaucum & $\begin{array}{c}\text { Características morfológicas e } \\
\text { trocas gasosas }\end{array}$ & Izidro (2019) \\
\hline Irrigação & Sorgo & Sorghum bicolor & $\begin{array}{c}\text { Índice de área foliar, } \\
\text { condutância estomática, taxa } \\
\text { fotossintética e taxa de } \\
\text { transpiração }\end{array}$ & Zwirtes (2013) \\
\hline Irrigação & Palma forrageira & Opuntia stricta & Não apresentou alterações & $\begin{array}{l}\text { Queiroz et al. } \\
\qquad(2015)\end{array}$ \\
\hline
\end{tabular}

Fonte: Autores.

Como observado na Tabela 1, a escolha do manejo do cultivo por meio da alteração da densidade de plantas busca a otimização na eficiência do uso dos recursos disponíveis, de modo que o acréscimo na densidade de plantas e a redução no espaçamento entre fileiras, promove maior eficiência na interceptação luminosa, uma vez que ocorre o aumento no índice de área foliar (Amaral Filho et al., 2005). Magalhães et al. (2011) estudando a cultura do capim-Tanzânia observaram que o acréscimo na densidade de plantas promoveu modificações na taxa de alongamento foliar, entretanto quando avaliado a taxa de aparecimento foliar e o filocrono, não houve influência. Sob condições de maiores densidades a taxa de alongamento do pseudocolmo tende a se elevar, isso se deve a maior necessidade em captação da radiação fotossinteticamente ativa das folhas (Magalhães et al., 2011).

Com a redução do espaçamento entre plantas, a competição intraespecífica, principalmente por luz, reduz o número de ramificações, devido à uma redução na disponibilidade de fotoassimilados responsáveis pelo crescimento vegetativo das culturas em forma de ramificações (Mauad et al., 2010). Por outro lado, o aumento da densidade de plantas promove a inserção da primeira vagem na soja, sendo uma característica importante, uma vez que determina a regulagem do implemento no momento da colheita, visando uma maior eficiência durante o processo (Mauad et al., 2010).

Ainda na Tabela 1, é possível confirmar que a aplicação de adubo nitrogenado é de suma importância quando se avalia os aspectos de produtividade das culturas, principalmente quanto à sua influência nas características morfofisiológicas das plantas forrageiras. A utilização de adubação nitrogenada busca o suprimento do nutriente nitrogênio nas plantas, uma vez 
que participa de diversas atividades metabólicas relacionadas a sobrevivência da cultura, participando ativamente da produção, principalmente no aumento da área foliar, produção de matéria seca e grãos (Ferreira et al, 2001; Araújo, Ferreira \& Cruz, 2004). Esse nutriente afeta as características morfofisiológica das culturas forrageias, influenciando diretamente no fluxo de tecidos, podendo afetar a altura do dossel e consequentemente a interceptação luminosa, por acelerar o processo de crescimento e senescência, atingindo 95 \% da interceptação luminosa quando aplicado maiores doses de nitrogênio (Magalhães et al., 2011).

Além do nitrogênio, um nutriente que limita bastante a produção de forragem é o fósforo, pois desempenha funções importantes relacionadas ao crescimento inicial das culturas, associado a atividade dos meristemas, desenvolvimento das raízes, perfilhamento, emissão de estolões, dentre outras atividades necessárias para os vegetais (Zucareli et al., 2006; Rezende et al., 2011). Quando submetido a adubação fosfatada, o número de perfilho é maior se comparada a plantas que não recebem essa adubação. Além disso, o fósforo desempenha importante papel na taxa de crescimento inicial das plantas, bem como seu estabelecimento, de tal modo, que sua deficiência reduz tais características (Rezende et al., 2011).

Outro macronutriente que apresenta elevada importância para a nutrição dos vegetais é o potássio, o qual participa diretamente nas funções fisiológicas e metabólicas, tais como ativação de enzimas, atividade fotossintética, translocação de assimilados e participa na síntese proteica (Andrade et al., 2003). O incremento na aplicação de potássio favorece o perfilhamento, influenciando diretamente na produção da cultura, além disso as doses potássicas influenciam no número de folhas vivas, na taxa de senescência foliar, taxa de alongamento foliar e duração da vida das folhas (Sanchês et al., 2013).

Com o intuito de maximizar a produção e diversificar o cultivo, o emprego de sistema consorciado se torna uma prática indispensável, uma vez que tem por propósito o cultivo de duas ou mais espécies diferentes em uma mesma área simultaneamente (Alves et al., 2018; Qian et al., 2018). O emprego do consórcio pode promover certas alterações morfofisiológica nas plantas forrageiras. Sob consórcio, a palma forrageira, ótima fonte de alimento para os animais, principalmente em ambiente semiárido, apresenta modificações quanto a suas características, de tal modo que a consorciação com milheto promove redução da segunda fase fenológica da cultura, a qual representada a taxa máxima de emissão de cladódios de segunda ordem, indicando que o sistema consorciado antecipa a emissão de cladódios de terceira ordem, a qual caracteriza o início da fase três (Souza, 2019). Entretanto, Lins et al. (2015) estudando o consórcio de capim-Tanzânia com estilosantes, evidenciaram que este sistema não promove alterações na taxa de aparecimento foliar e filocrono, os autores relataram que esse resultado está associado as temperaturas ocorridas durante o período experimental e ao manejo realizado, vale ressaltar que as plantas estavam sob pastejo.

Outro manejo a ser levando em consideração no momento do cultivo é a utilização de cobertura morta, a qual promove melhorias nas condições físicas, térmicas e hídricas do solo, favorecendo um melhor desenvolvimento da cultura (Alves et al., 2018). Sob a aplicação de cobertura morta as características morfofisiológicas das plantas tendem a ser modificadas. Plantas submetidas a condições de ausência de cobertura apresentaram redução de área foliar quando comparada as plantas que estão sob o uso de cobertura morta, isso se deve principalmente as condições de maior retenção de água no solo, influenciando diretamente nas características morfológicas das plantas (Izidro, 2019). Ao avaliar as trocas gasosas em plantas submetidas à presença de cobertura morta no solo, Izidro (2019) percebeu uma influência positiva e proporcional devido às respostas na taxa de assimilação líquida de $\mathrm{CO}$, condutância estomática e eficiência no uso da água, ou seja, quanto maior o nível de cobertura aplicado, melhores foram as respostas, em cultivo de milheto.

$\mathrm{O}$ uso de irrigação busca o suprimento hídrico das culturas, influenciando diretamente em seu crescimento e desenvolvimento. Em estudo com gramíneas (i. e. sorgo) sob diferentes lâminas de irrigação foi constatado que quanto maior a lâmina de irrigação aplicada melhores são as características morfofisiológicas (e. g. altura de planta, índice de área foliar, condutância estomática e taxa fotossintética), apresentando comportamento linear negativo com a redução da lâmina de 
irrigação, demonstrando a importância dessa prática sobre as características produtivas dos vegetais (Zwirtes, 2013). Entretanto, se tratando da palma forrageira essas modificações morfofisiológicas não são evidenciadas, quando aplicadas diferentes lâminas de irrigação no solo (Queiroz et al., 2015), não contribuindo com aumento de seu rendimento, sendo o ideal para esta cultura lâminas entre 1048 a 1090 mm/ano. Tal fato se deve principalmente pela adoção de uma espécie altamente adaptada às regiões áridas e semiáridas do globo terrestre, uma vez que a palma tolera longos períodos de estiagem e apresenta alta eficiência no uso da água (Lima et al., 2018), sendo considerada uma espécie agrícola resiliente, pois resiste às adversidades climáticas (Carvalho et al., 2017).

\subsubsection{Animal $x$ morfofisiologia das plantas forrageiras}

Um dos sistemas de manejo que merece destaque quando se refere a plantas forrageias é o sistema de pastejo (Figura 3), uma vez que, os sistemas de produção brasileiros, principalmente de bovinos, são baseados em pastagens (Paciullo et al., 2007).

O pastejo apresenta pontos positivos e negativos, quando avaliado as características das plantas. Avaliando diferentes métodos de pastejo em Carex duriuscula, Liu e Li (2010), observaram que as características morfofisiológicas dessa espécie são altamente responsivas aos diferentes métodos de pastejo, onde foram negativamente relacionados ao período, ou seja, quanto maior o período de pastejo, menores são os índices, logo, métodos de pastejo que há menores períodos e intensidades, impactam menos a forragem, como foi encontrado no pastejo rotacionado para este experimento ( $\mathrm{Liu} \& \mathrm{Li}$, 2010). Já o aspecto positivo está relacionado com o benefício promovido, em que após a desfolha causada pelo pastejo ocorre um crescimento compensatório dos órgãos e tecidos da planta e que segundo Ferraro e Oesterheld (2002), é uma resposta comum da planta ao pastejo, sendo este influenciado e governado por diversos mecanismos. Dentre esses, está na maior alocação de carboidratos, que estavam armazenados no colmo e raízes, para as folhas. Além disso, ocorre também a mobilização de reservas de nitrogênio, das raízes e caules para as folhas em desenvolvimento (Liu \& Li, 2010). Outro fator bastante preponderante para o desenvolvimento da forragem, após a desfolha, está na maior penetração da luz solar no dossel da planta, havendo maior atividade fotossintética, remoção de folhas velhas e ativação de meristemas dormentes (Costa et al., 2004). 
Figura 3. Presença de animas na área de pastagem, influencia diretamente nas modificações morfofisiológica das plantas forrageiras

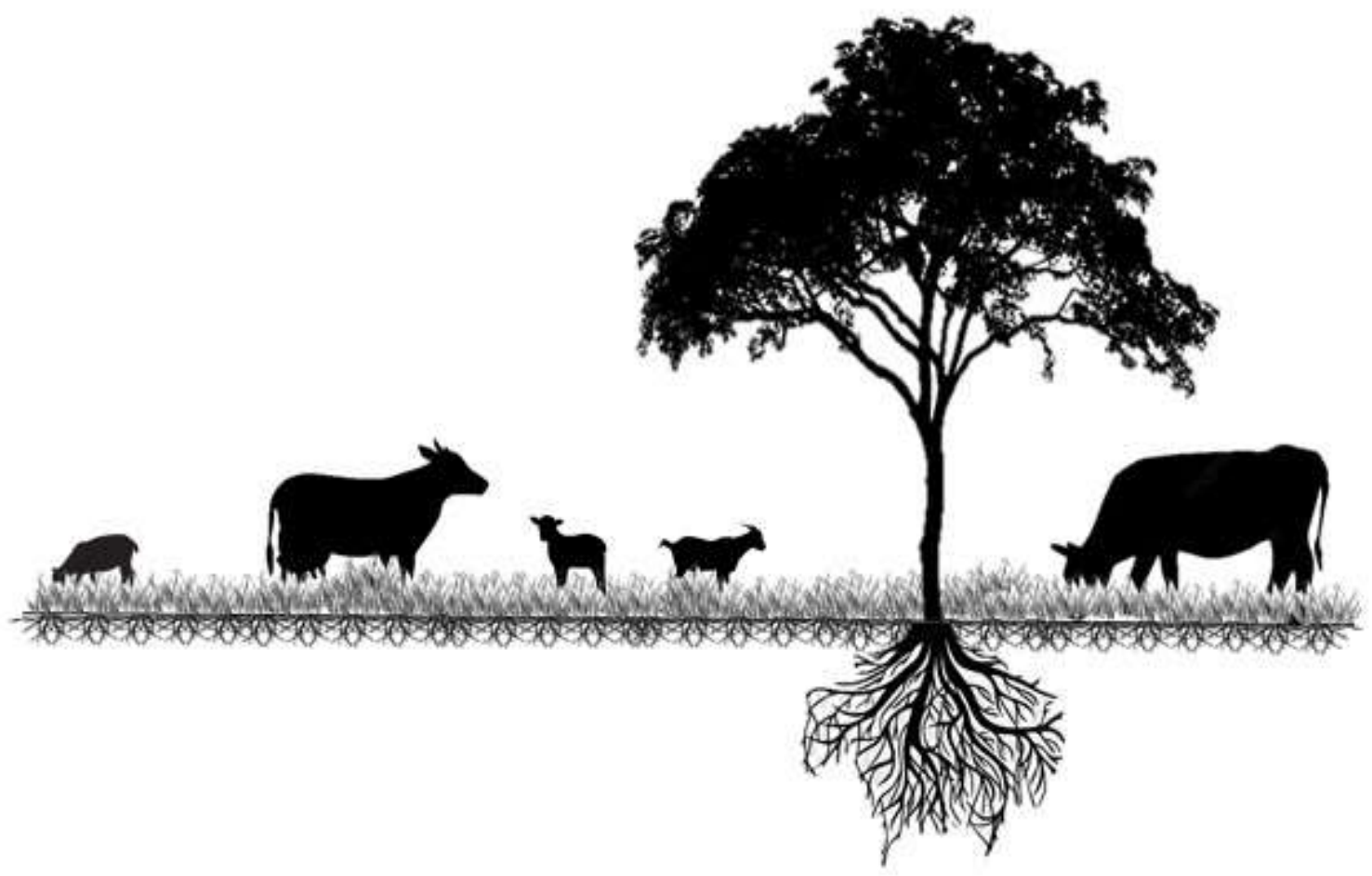

Fonte: Autores.

É de suma importância a condução correta dos animais sob pastejo, uma vez que promovem alterações na dinâmica de crescimento e desenvolvimento das culturas que compõem a pastagem, influenciando em modificações na morfofisiologia das plantas, por meio da intensidade de manejo. Uma característica influenciada diretamente pela intensidade de pastejo é a altura do dossel e a taxa de alongamento de colmo, as quais apresentam comportamento linear positivo com o aumento na oferta de forragem, ou seja, com uma menor intensidade de pastejo (Casagrande et al., 2010).

Casagrande et al. (2010) relataram que a influência nas características morfogênicas e estruturais das plantas são mais influenciadas pelas condições climáticas que pelo manejo aplicado.

Um manejo inadequado promove alterações na capacidade da cultura em rebrotar, influenciando diretamente na produtividade de forragem e por consequência no desempenho animal, um desses manejos é o superpastejo, o qual é caracterizado pela lotação animal superior a capacidade suporte da forragem. Dessa maneira o ajustamento na taxa de lotação promove um aumento na capacidade do produtor em aumentar sua renda, com isso o aumento na oferta de forragem reflete em aumento linear na massa de lâmina foliar e altura do dossel (Machado et al., 2007).

O uso correto da oferta de forragem, é uma estratégia eficiente para a manutenção da sustentabilidade do pasto, fazendo com que se tenha uma melhor disponibilidade de massa de forragem, contribuindo para uma maior otimização do pastejo pelos animais e assim permitindo a renovação dos componentes morfológicos do dossel forrageiro (Janusckiewicz et al., 2016). Casagrande et al. (2010), avaliando o uso de diferentes ofertas de forragem com capim-Marandu, concluíram que a morfofisiologia da planta forrageira é bastante afetada pela oferta de forragem, principalmente nas características de alongamento de colmo e densidade de perfilhos, ainda nesse estudo, os autores concluíram que para o capim marandu uma 
oferta de $4 \mathrm{~kg}$ por $100 \mathrm{~kg}$ de peso vivo promove menor alongamento de colmos, reduzindo assim as perdas por senescência. Além disso, a capacidade de suporte é também um fator determinante para o ecossistema de pastagem, pois a partir dela é possível evitar a degradação das pastagens, na qual, quanto maior for a taxa de lotação, maior será a frequência de desfolhação. Neste sentido, a desfolha influencia diretamente nos atributos morfofisiológicos das plantas, em que durante o evento da desfolha, ocorre redução da área foliar alterando o equilíbrio entre o crescimento de raiz, caule, folhas e inflorescência e, consequentemente a taxa fotossintética; diminuindo a distribuição de assimilados para a raiz e interferindo na relação folha/caule, a depender do estádio de maturação dos perfilhos (Rezende, 2003).

Uma resposta comum a desfolha é a emissão de folhas. Avaliando as características morfogênicas de capim-cameroon e capim-braquiarão sob diferentes taxas de lotação, Rezende (2003), observou que com o aumento da intensidade de desfolha provocada pelo aumento da taxa de lotação nos capins estudados, observou-se que houve a emissão de um maior número de folhas. Portanto, a habilidade das plantas forrageiras em manter a produção foliar, sob desfoliação periódica, é essencial para a manutenção da sustentabilidade da pastagem e assim assegurar a sobrevivência das plantas pastejadas (Rezende, 2003).

Mesmo as plantas apresentando uma capacidade de rebrota bastante elevada, as pressões de pastejo podem interferir diretamente a produtividade de diversas culturas. Pressões de pastejo elevadas, podem promover uma redução de área foliar, além de aumentar a matéria morta e reduzir as taxas fotossintéticas da planta, fatores essenciais para a produção e qualidade do pastejo. Porém, a partir de uma certa lotação, as áreas de pastejo poderão sofrer degradações, a situação pode ser gravemente agravada em caso de falta de adubação, em que a planta sendo pisoteada começa consumir suas reservas para suprir a necessidade de rebrota e reduz a suas atividades fotossintéticas (Silveira et al 2012).

As principais estratégias para incrementar a capacidade de suporte são: aumentar a quantidade de forragem, melhorar a qualidade da forragem e intensificar a eficiência de uso da forragem pelos animais.

\section{Considerações Finais}

As características morfofisiológicas das plantas forrageiras são influenciadas pelo manejo aplicado, onde os fatores que afetam a morfofisiologia variam em função de cada espécie forrageira. O planejamento agrícola é um passo crucial para o manejo das plantas forrageiras, pois assim permanecerá produtivo e capaz de proporcionar alimento para os animais, por maios tempo. Por fim, para maior lucratividade na produção, deve-se sempre considerar as condições de cultivo, uso de espécies adequadas para a região, adequação na taxa de lotação animal, adoção de manejos de cultivo e também se atentar quanto às condições climáticas locais, sem promover prejuízos sociais, econômicos e ambientais.

Sugere-se o desenvolvimento de estudos voltados ao entendimento do crescimento e desenvolvimento das plantas forrageiras sob modificação do manejo de cultivo, possibilitando a recomendação dos melhores sistemas, para obtenção de maiores rendimentos de modo sustentável e com relações solo-planta-animal-atmosfera positivas.

\section{Referências}

Almeida, J. C., Rocha, N. S., Nepomuceno, D. D., Araújo, R. P., Silva, T. O., Morenz, M. J. F., \& Macedo, R. O. (2015). Composição mineral de leguminosas forrageiras cultivadas sob diferentes níveis de sombreamento. Semina: Ciências Agrárias, 36(1), 367-375.

Alves, H. K. M. N., Jardim, A. M. R. F., Souza, L. S. B., \& Silva, T. G. F. (2018). The application of agrometeorological techniques contributes to the agricultural resilience of forage cactus: A review. Amazonian Journal of Plant Research, 2(3), 207-220.

Amaral Filho, J. P. R. D., Fornasieri Filho, D., Farinelli, R., \& Barbosa, J. C. (2005). Row spacing, population density and nitrogen fertilization in maize. Revista Brasileira de Ciência do Solo, 29(3), 467-473.

Andrade, A. C., Fonseca, D. D., Queiroz, D. S., Salgado, L. T., \& Cecon, P. R. (2003). Adubação nitrogenada e potássica em capim-elefante (Pennisetum purpureum Schum. cv. Napier). Ciência e Agrotecnologia, 27, 1643-1651.

Araújo, L. A. N. D., Ferreira, M. E., \& Cruz, M. C. P. D. (2004). Adubação nitrogenada na cultura do milho. Pesquisa Agropecuária Brasileira, 39(8), 771777. 
Biglari, T., Maleksaeidi, H., Eskandari, F., \& Jalali, M. (2019). Livestock insurance as a mechanism for household resilience of livestock herders to climate change: evidence from Iran. Land Use Policy, 87, 104043.

Cândido, M. J. D., Gomide, C. A. M., Alexandrino, E., Gomide, J. A., \& Pereira, W. E. (2005). Morfofisiologia do dossel de Panicum maximum cv. Mombaça sob lotação intermitente com três períodos de descanso. Revista Brasileira de Zootecnia, 34(2), 406-415.

Carvalho, A. A., Silva, T. G. F., Souza, L. S. B.; Moura, M. S. B., Araujo, G. G. L., \& Tolêdo, M. P. S. (2017). Soil moisture in forage cactus plantations with improvement practices for their resilience. Revista Brasileira de Engenharia Agrícola e Ambiental, (21), 481-487.

Casagrande, D. R., Ruggieri, A. C., Janusckiewicz, E. R., Gomide, J. A., Reis, R. A., \& Valente, A. L. D. S. (2010). Características morfogênicas e estruturais do capim-marandu manejado sob pastejo intermitente com diferentes ofertas de forragem. Revista Brasileira de Zootecnia, 39(10), $2108-2115$.

Costa, N. D. L., Magalhães, J. A., Townsend, C. R., \& Paulino, V. T. (2004). Fisiologia e manejo de plantas forrageiras. EMBRAPA Rondônia - Documentos (INFOTECA-E).

Durães, F. O. M., Magalhães, R. C., Costa, J. D., \& Fancelli, A. L. (1995). Fatores ecofisiológicos que afetam o comportamento do milho em semeadura. Scientia agrícola, 52(3), 491-501.

Diniz, W. J. D. S., Silva, T. G. F. D., Ferreira, J. M. D. S., Santos, D. C. D., Moura, M. S. B. D., Araújo, G. G. L. D., \& Zolnier, S. (2017). Forage cactussorghum intercropping at different irrigation water depths in the Brazilian Semiarid Region. Pesquisa Agropecuária Brasileira, 52(9), 724-733.

Dofing, S. M., \& Schmidt, J. W. (1984). Inheritance of Subcrown Internode Length in a Winter Barley Cross 1. Crop science, 24(4), 692-694.

Dutilly, C., Alary, V., Bonnet, P., Lesnoff, M., Fandamu, P., \& De Haan, C. (2019). Multi-scale assessment of the livestock sector for policy design in Zambia. Journal of Policy Modeling, 42(2), 401-418.

Erkossa, T., Williams, T. O., \& Laekemariam, F. (2018). Integrated soil, water and agronomic management effects on crop productivity and selected soil properties in Western Ethiopia. International Soil and Water Conservation Research, 6(4), 305-316.

Fagundes, J. L., Fonseca, D. M. D., Morais, R. V. D., Mistura, C., Vitor, C. M. T., Gomide, J. A., \& Lambertucci, D. M. (2006). Avaliação das características estruturais do capim-braquiária em pastagens adubadas com nitrogênio nas quatro estações do ano. Revista Brasileira de Zootecnia, 35(1), 30-37.

Ferreira, A. C. D. B., Araújo, G. A. D. A., Pereira, P. R. G., \& Cardoso, A. A. (2001). Características agronômicas e nutricionais do milho adubado com nitrogênio, molibdênio e zinco. Scientia Agricola, 58(1), 131-138.

Ferraro, D. O.; Oesterheld, M. (2002). Effect of defoliation on grass growth: a quantitative review. Oikos, 98(1), $125-133$.

Freitas, E. C. S., Oliveira Neto, S. N., Fonseca, D. M., Santos, M. V., Leite, H. G., \& Machado, V. D. (2013). Deposição de serapilheira e de nutrientes no solo em sistema agrossilvipastoril com eucalipto e acácia. Revista Árvore, 37(3), 409-417.

Gobbi, K. F., García, R., Garcez Neto, A. F., Pereira, O. G., \& Rocha, G. C. (2010). Valor nutritivo do capim-braquiária e do amendoim forrageiro submetidos ao sombreamento. Archivos de Zootecnia, 59(227), 379-390.

Gomes, K. R., Amorim, A. V., Ferreira, F. J., A Filho, F. L., Lacerda, C. F., \& Gomes-Filho, E. (2011). Respostas de crescimento e fisiologia do milho submetido a estresse salino com diferentes espaçamentos de cultivo. Revista Brasileira de Engenharia Agrícola e Ambiental, 15(4), 365-370.

Hyder, D. N., Everson, A. C., \& Bement, R. E. (1971). Seedling morphology and seeding failures with blue grama. Rangeland Ecology \& Management/Journal of Range Management Archives, 24(4), 287-292

Izidro, J. L. P. S. (2019). Propriedades do solo, características agronômicas e trocas gasosas do milheto em função da adubação orgânica e cobertura morta no solo em ambiente semiárido. Dissertação de mestrado, Universidade Federal Rural de Pernambuco, Serra Talhada, PE, Brasil.

Janusckiewicz, E. R.; Raposo, E.; Morgado, E. S.; Reis, R. A.; Ruggieri, A. C. (2016). Perfil morfofisiológico de capim-marandu manejado sob diferentes ofertas de forragem e pastejado por vacas leiteiras. Ars veterinaria, 32 (1), 67-73.

Liu, Z. G.; Li, \& Z. Q. (2010). Effects of different grazing regimes on the morphological traits of Carex duriuscula on the Inner Mongolia steppe, China. New Zealand Journal of Agricultural Research, 53 (1), 5-12.

Lima, L. R., Silva, T. G. F., Pereira, P. C., Morais, J. E. F., \& Assis, M. C. S. (2018). Productive-economic benefit of forage cactus-sorghum intercropping systems irrigated with saline water. Revista Caatinga, (31), 191-201.

Lins, T. O. J. D. A., Cecato, U., Pinheiro, A. A., Iwamoto, B. S., Krutzmann, A., Beloni, T., \& Silva, R. R. (2015). Características morfogênicas do capimTanzânia consorciado com Estilosantes Campo Grande ou adubado com nitrogênio sob pastejo. Semina: Ciências Agrárias, 36(4), $2739-2752$.

Lovelli, S., Perniola, M., Di Tommaso, T., Ventrella, D., Moriondo, M., \& Amato, M. (2010). Effects of rising atmospheric CO2 on crop evapotranspiration in a Mediterranean area. Agricultural Water Management, 97(9), 1287-1292.

Machado, L. A. Z., Fabrício, A. C., Assis, P. G. G. D., \& Maraschin, G. E. (2007). Estrutura do dossel em pastagens de capim-marandu submetidas a quatro ofertas de lâminas foliares. Pesquisa Agropecuária Brasileira, 42(10), 1495-1501.

Magalhães, M. D. A., Martuscello, J. A., Fonseca, D. M. D., Oliveira, I. M. D., Freitas, F. P. D., Faria, D. J. G., \& Ribeiro Júnior, J. I. (2011). Influência da irrigação, da densidade de plantio e da adubação nitrogenada nas características morfogênicas, estruturais e de produção do capim-tanzânia. Revista Brasileira de Zootecnia, 40(11), 2308-2317.

Martin, J. M., Smith, C. W., \& Ferguson, A. H. (1988). Subcrown internode length of spring wheat and barley as influenced by light and soil temperature. Agronomy Journal, 80(4), 571-573. 
Mauad, M., Silva, T. L. B., Neto, A. I. A., \& Abreu, V. G. (2010). Influência da densidade de semeadura sobre características agronômicas na cultura da soja. Agrarian, 3(9), 175-181.

Mello Ivo, W. M. P. D., \& Mielniczuk, J. (1999). Influência da estrutura do solo na distribuição e na morfologia do sistema radicular do milho sob três métodos de preparo. Revista Brasileira de Ciência do Solo, 23(1), 135-143.

Milhorance, C., Mendes, P., Mesquita, P., Morimura, M., Reis, R., Rodrigues Filho, S., \& Bursztyn, M. (2019). O desafio da integração de políticas públicas para a adaptação às mudanças climáticas no Semiárido brasileiro. Revista Brasileira de Climatologia, 24, 175-195.

Mozambani, A. E., \& Bicudo, S. J. (2009). Efeito da temperatura e da luz no desenvolvimento de plântulas de milho. Nucleus, 6(1), 1-12.

Nascimento, M. E., Bertolucci, S. K. V., Santos, F. M., Santos Jr, J. M., Castro, E. M., \& Pinto, J. E. B. P. (2014). Avaliação morfológica de plantas jovens de Copaifera langsdorffii Desf. desenvolvidas em diferentes temperaturas. Revista Brasileira de Plantas Medicinais, 16(4), 931-937.

Nogueira, S. D. S. S., \& Manfredini, S. (1983). Influência da compactação do solo no desenvolvimento da soja. Pesquisa Agropecuária Brasileira, 18(9), 969976.

Paciullo, D. S. C., De Carvalho, C. A. B., Aroeira, L. J. M., Morenz, M. J. F., Lopes, F. C. F., \& Rossiello, R. O. P. (2007). Morfofisiologia e valor nutritivo do capim-braquiária sob sombreamento natural e a sol pleno. Pesquisa Agropecuária Brasileira, 42(4), 573-579.

Parfitt, J. M. B. (2000). Produção de milho e sorgo em várzea. Embrapa Clima Temperado. Recuperado de https://www.infoteca.cnptia.embrapa.br/infoteca/bitstream/doc/743586/2/Docu

mento74.pdf

Pereira, A. S., Shitsuka, D. M., Parreira, F. J., Shitsuka, R. (2018). Metodologia da Pesquisa Científica. Santa Maria, Brasil: Núcleo de Tecnologia Educacional da Universidade Federal de Santa Maria.

Pompeu, R. C. F. F., Cândido, M. J. D., Lopes, M. N., Gomes, F. H. T., Lacerda, C. F. D., Aquino, B. F., \& Magalhães, J. A. (2010). Características morfofisiológicas do capim-aruana sob diferentes doses de nitrogênio. Revista Brasileira de Saúde e Produção Animal, 11(4), 1187-1210.

Qian, X., Zang, H., Xu, H., Hu, Y., Ren, C., Guo, L., \& Zeng, Z. (2018). Relay strip intercropping of oat with maize, sunflower and mung bean in semi-arid regions of Northeast China: yield advantages and economic benefits. Field Crops Research, 223, 33-40.

Queiroz, M. G., Silva, T. G. F., Zolnier, S., Silva, S. M. S., Lima, L. R., \& Alves, J. O. (2015). Características morfofisiológicas e produtividade da palma forrageira em diferentes lâminas de irrigação. Revista Brasileira de Engenharia Agricola e Ambiental, 19(10), 931-938.

Rezende, C. P. Ganho de peso e características pastagens de capim-cameroon e capim-braquiarão sob diferentes taxas de lotação. Tese (Doutorado em Forragicultura e Pastagens), Universidade Federal de Lavras, Lavras, MG, Brasil.

Rezende, A. V., Lima, J. F., Rabelo, C. H. S., Rabelo, F. H. S., Nogueira, D. A., Carvalho, M., \& Barbosa, L. A. (2011). Características morfofisiológicas da Brachiaria brizantha cv. Marandu em resposta à adubação fosfatada. Agrarian, 4(14), 335-343.

Rosolem, C. A., Mateus, G. P., Godoy, L. J. G., Feltran, J. C., \& Brancalião, S. R. (2003). Morfologia radicular e suprimento de potássio às raízes de milheto de acordo com a disponibilidade de água e potássio. Revista Brasileira de Ciência do Solo, 27(5), 875-884.

Sanchês, S. S. C., Galvão, C. M. L., Rodrigues, R. C., Siqueira, J. C., Jesus, A. P. R., Araújo, J. S., \& Silva Junior, A. L. (2013). Produção de forragem e características morfofisiológicas do capim-mulato cultivado em latossolo do cerrado em função de doses de nitrogênio e potássio. Revista Brasileira de Agropecuária Sustentável, 3(1), 81-89, 2013.

Santos, N. L., Silva, V. C., Martins, P. E. S., Alari, F. O., Galzerano, L., \& Miceli, N. G. (2011). As alterações entre solo, planta e animal no ecossistema pastoril. Ciência Animal, 21(1), 65-76.

Silveira, E. R., Pelissari, A., de Moraes, A., von Linsingen Piazzetta, H., Lang, C. R., \& de Faccio Carvalho, P. C. (2012). Intensidade de pastejo e adubação nitrogenada na massa seca de aveia e produtividade do milho na integração lavoura-pecuária. Semina: Ciências Agrárias, 33(4), 1323-1331.

Soares, A. B., Sartor, L. R., Adami, P. F., Varella, A. C., Fonseca, L., \& Mezzalira, J. C. (2009). Influência da luminosidade no comportamento de onze espécies forrageiras perenes de verão. Revista Brasileira de Zootecnia, 38(3), 443-451.

Souza, M. S. (2019). Desempenho agronômico do consorcio palma-milheto com cobertura morta em ambiente Semiárido. Dissertação de mestrado, Universidade Federal Rural de Pernambuco, Serra Talhada, PE, Brasil.

Zilliani, R. R. (2015). Influência de biorreguladores sobre a fisiologia e crescimento inicial de cana-de-açúcar submetida ao déficit hídrico. Dissertação de mestrado, Universidade do Oeste Paulista, Presidente Prudente, SP, Brasil.

Zucareli, C., Ramos Junior, E. U., Barreiro, A. P., Nakagawa, J., \& Cavariani, C. (2006). Adubação fosfatada, componentes de produção, produtividade e qualidade fisiológica em sementes de feijão. Revista Brasileira de Sementes, 28(1), 9-15.

Zwirtes, A. L. (2013). Características morfofisiológica e produtiva de plantas de sorgo submetidos à irrigação deficitária. Dissertação de mestrado, Universidade Federal de Santa Maria, Santa Maria, RS, Brasil. 